\title{
Risk factors for the local recurrence of hepatocellular carcinoma after single-session percutaneous radiofrequency ablation with a single electrode insertion
}

\author{
KAZUE SHIOZAWA, MANABU WATANABE, NORITAKA WAKUI, TAKASHI IKEHARA, \\ KAZUNARI IIDA and YASUKIYO SUMINO \\ Division of Gastroenterology and Hepatology, Toho University Medical Center, \\ Omori Hospital, 6-11-1 Omorinishi, Ota-ku, Tokyo 143-8541, Japan
}

Received August 12, 2008; Accepted November 3, 2008

DOI: 10.3892/mmr_00000067

\begin{abstract}
Radiofrequency ablation (RFA) is a new local therapy for hepatocellular carcinoma (HCC). In this study, we investigated the risk factors associated with local recurrence of HCC after single-session RFA with a single electrode insertion. From April 2003 to December 2007, we treated 138 HCC lesions by single-session RFA with a single electrode insertion using the Cool-tip RFA, RTC 2000 and RTC 3000 Systems. Risk factors for the local recurrence of these lesions and complications after RFA were analyzed. The mean size of the 138 lesions was $16.9 \pm 5.4 \mathrm{~mm}$ in diameter (range 7-33 mm). Local recurrence rates were 6.6 and $22.0 \%$ at 1 and 2 years, respectively, during the mean follow-up period of 16.4 months. Univariate analysis showed that tumor diameter $(\geq 20 \mathrm{~mm})$, tumor location, pre-treatment AFP-L3 fraction level and ablation pattern were significant variables. Multivariate analysis of these four variables identified only the tumor diameter as an independent risk factor for local recurrence. Complications occurred in $2.2 \%$ of the lesions (3/138). Single-session RFA is an effective treatment for $\mathrm{HCC}$ in that it reduces serious complications. This study demonstrated that a tumor size $\geq 20 \mathrm{~mm}$ influenced the local recurrence of single-session RFA with a single electrode insertion.
\end{abstract}

\section{Introduction}

Hepatocellular carcinoma (HCC) is one of the most common cancers worldwide and occurs in association with liver cirrhosis. Surgical resection has been found to be a very effective treatment for the prevention of the local recurrence of HCC. However, in most patients with HCC, surgical resection is

Correspondence to: Dr Kazue Shiozawa, Division of Gastroenterology and Hepatology, Toho University Medical Center, Omori Hospital 6-11-1, Omorinishi, Ota-ku, Tokyo 143-8541, Japan

E-mail:k.shio@med.toho-u.ac.jp

Key words: hepatocellular carcinoma, radiofrequency ablation, local recurrence, single session limited by liver dysfunction caused by liver cirrhosis. Thus, minimally invasive approaches, which are effective and repeatable, are desirable for most patients with HCC.

Local therapies for HCC, such as percutaneous ethanol injection therapy (PEIT) (1), percutaneous microwave coagulation therapy (PMCT) (2) and percutaneous radiofrequency ablation therapy (RFA), appear to be beneficial mainly for treating solitary small $\mathrm{HCC}(3,4)$. RFA for HCC is capable of ablating a wide area in a single session, and is therefore considered to require fewer sessions for more effective local control compared to PEIT and PMCT. Recently, RFA has emerged as an alternative to PEIT and PMCT. RFA is less invasive than surgical resection, and reportedly produces results comparable to those of radical surgical resection, particularly in patients with a tumor diameter less than $30 \mathrm{~mm}$ (5). Consequently, RFA has recently been evaluated regarding its efficacy $(1,6,7)$.

It is known that HCC occurs multicentrically and frequently metastasizes intrahepatically. The reported 1-, 2- and 3-year local recurrence rates of HCC after RFA are 1.3-24, 2.4-36.4 and $2.4-46.6 \%$, respectively $(6,8-16)$. To achieve better therapeutic effects, it is important to sufficiently control local recurrence after RFA, and the analysis of factors involved in local recurrence is essential. Further multiple-session RFA has been reported to increase the incidence of complications, such as bleeding and tumor seeding, and to promote the rapid progression of HCC $(17,18)$. Therefore, we attempted to perform single-session RFA with a single electrode insertion. Here, we report the evaluation of single-session RFA based on local recurrence rates, factors associated with local recurrence and complications in patients who had previously undergone RFA in our hospital.

\section{Subjects and methods}

From among 118 HCC patients who had undergone RFA at our hospital between April 2003 and December 2007, 138 lesions, excluding local recurrent lesions which had undergone singlesession RFA, were included. The RFA systems used were the Csool-tip RFA System (Covidien, Boulder, CO, USA) and the RTC 2000 and 3000 Systems (Boston Scientific Inc., Natick, MA, USA). All patients underwent ultrasound (US)guided RFA. For lesions that were immediately in the 
vicinity of a subcapsular location or diaphragmatic dome, making them difficult to visualize by US, artificial pleural or ascitic fluid (500-1,000 $\mathrm{ml}$ of 5\% glucose solution) was used to facilitate their visualization.

The Cool-tip RFA System and RTC 2000 and 3000 Systems were employed to ablate 93 and 45 lesions, respectively. RFA was performed using different needle electrodes as follows: i) the Cool-tip RFA System was used with a 17-gauge cooled-tip electrode with a 20-mm exposed tip. Initial power output was $40 \mathrm{~W}$. This was then increased by $10 \mathrm{~W}$ every minute to a maximum of $60 \mathrm{~W}$, and RF energy delivery was conducted three times until impedance increased beyond the limit of the generator. ii) The RTC 2000 and 3000 Systems were used with a LeVeen needle outer 15 -gauge electrode. The maximum dimension was 30 and $35 \mathrm{~mm}$ on full expansion. The electrode was slightly expanded at the base of the tumor according to its size, and initial power output was 30-40 W. This was then increased by $10 \mathrm{~W}$ every minute until reaching the maximum suitable for the diameter of the needle expansion, and then maintained until roll-off occurred. Subsequently, the needle electrode was fully expanded and initial power output was set to $40 \mathrm{~W}$. This was increased by $10 \mathrm{~W}$ every minute until power output reached 90-120 W. Power was then maintained until roll-off occurred. After a 30 -sec pause, power was reapplied at $70 \%$ of the maximum output achieved until power roll-off again occurred. If the area of necrosis was insufficient, the needle electrode was moved 5-10 mm upward under US monitoring, and ablation was repeated (stepwise expansion technique).

Therapeutic effect was assessed by contrast-enhanced CT (CE-CT) of the abdomen 3-5 days after RFA. The ablated area was considered adequate if the pre-treatment tumor enhancement disappeared completely in the early phase and the ablated area circumferentially exceeded the border between the pre-treatment tumor margin and non-tumor area in the portal-dominant phase. The ablation pattern was defined according to the degree of ablation achieved as follows: R1, ablative margin is $5 \mathrm{~mm}$ or wider all around the tumor; R2, ablative margin is formed all around the tumor, but is $<5-\mathrm{mm}$ wide in some places; and R3, a complete ablative margin is not formed, although no residual tumor is apparent (Fig .1).

Follow-up was carried out every 3-4 months after RFA using CE-CT and US. When HCC was identified within or in contact with the ablated area during the follow-up period after RFA, it was considered to be local recurrence.

The following 11 variables were analyzed in terms of their association with local recurrence: age ( $\geq 65$ vs. $<65$ years), background liver [chronic hepatitis $(\mathrm{CH})$ vs. liver cirrhosis (LC)], etiology (HBV vs. HCV vs. non-B non-C virus), ChildPugh classification (A vs. B or C), tumor diameter ( $\geq 20$ vs. $<20 \mathrm{~mm}$ ), tumor location (subcapsular vs. non-subcapsular), pre-treatment AFP level ( $\geq 20 \mathrm{vs} .<20 \mathrm{ng} / \mathrm{ml}$ ), pre-treatment AFP-L3 fraction level ( $\geq 10$ vs. $<10 \%$ ), pre-treatment PIVKA II level ( $\geq 40$ vs. $<40 \mathrm{mAU} / \mathrm{ml}$ ), presence or absence of initial treatment, and ablation pattern (R1 vs. R2 vs. R3). The local recurrence rate for each variable was computed by KaplanMeier estimates. For each variable analyzed, differences in the curves were tested with the log-rank test. Parameters assessed before treatment that proved to be significant on univariate analysis were tested by the multivariate Cox's proportional

\section{R1 (absolutely curative): ablative margin is $\geq 5 \mathbf{~ m m}$ all around the tumor.}
R2 (relatively curative): ablative margin is formed all around the tumor, but is $<5 \mathbf{~ m m}$ wide in some places.

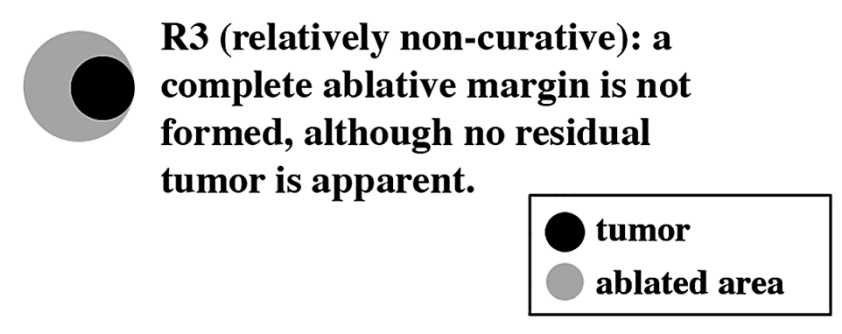

Figure 1 . The radicality of radiofrequency ablation (RFA) was classified into 3 grades (R1, R2 and R3) according to the extent of the ablated area around the tumor for use in assessing therapeutic effect.

hazards model. P-values $<0.05$ were considered to be statistically significant.

Adverse events, such as prolonged hospitalization after RFA, were considered to be complications.

This study was approved by the ethics committee of Toho University Medical Center, Omori Hospital, Tokyo, Japan.

\section{Results}

The subjects consisted of 86 men (102 lesions) and 32 women (36 lesions) with a mean age of $68.2 \pm 8.3$. Patients aged $\geq 65$ years or $<65$ years with 92 and 46 lesions, respectively, underwent RFA. The background liver showed LC and $\mathrm{CH}$ in 120 and 18 lesions, respectively. The etiology was HBV, $\mathrm{HCV}$, and non-B non-C virus in 13, 111 and 14 lesions, respectively. In LC patients, the Child-Pugh classification was A in 88 and $\mathrm{B}$ or $\mathrm{C}$ in 32 lesions, respectively. Of the 138 lesions, 43 were initially treated for HCC (Table I).

Local recurrence rates were $6.6 \%$ at 1 year and $22.0 \%$ at 2 years during the mean follow-up period of 16.4 months (Fig. 2).

The mean tumor diameter was $19.8 \pm 6.5$ and $16.2 \pm 4.8 \mathrm{~mm}$ in the local and non-local recurrence groups, respectively. Forty-one and 97 lesions were $\geq 20$ and $<20 \mathrm{~mm}$ in diameter, respectively. Univariate analysis of variance showed a significant difference $(\mathrm{P}<0.0001)$ between tumor diameters $\geq 20$ and $<20 \mathrm{~mm}$.

There was a significant difference $(\mathrm{P}<0.0001)$ between tumor locations (subcapsular in 44 lesions vs. non-subcapsular in 94 lesions).

The mean pre-treatment AFP level was $50.5 \pm 60.8 \mathrm{ng} / \mathrm{ml}$ in the local recurrence group and $51.8 \pm 171.1 \mathrm{ng} / \mathrm{ml}$ in the non-local recurrence group, and the pre-treatment AFP level was $\geq 20 \mathrm{ng} / \mathrm{ml}$ in 55 lesions and $<20 \mathrm{ng} / \mathrm{ml}$ in 83 lesions. The mean pre-treatment AFP-L3 fraction level was 12.1 $\pm 15.3 \%$ in the local recurrence group and $7.5 \pm 12.2 \%$ in the non-local recurrence group, and the pre-treatment AFP-L3 fraction level 
Table I. Clinical background of the patients.

\begin{tabular}{|c|c|}
\hline Variable & \\
\hline Age (years) & $68.2 \pm 8.3($ range $42-86)$ \\
\hline Gender & \\
\hline Male & $102(74 \%)$ \\
\hline Female & $36(26 \%)$ \\
\hline Background of liver & \\
\hline $\mathrm{LC}$ & $120(87 \%)$ \\
\hline $\mathrm{CH}$ & $18(13 \%)$ \\
\hline Etiology & \\
\hline $\mathrm{HBV}$ & $13(9.4 \%)$ \\
\hline $\mathrm{HCV}$ & $111(80.5 \%)$ \\
\hline Other & $14(10.1 \%)$ \\
\hline Child-Pugh in LC patie & \\
\hline A & $88(73 \%)$ \\
\hline $\mathrm{B}$ or $\mathrm{C}$ & $32(27 \%)$ \\
\hline Tumor diameter (mm) & $16.9 \pm 5.4($ range $7.0-33.0)$ \\
\hline First therapy for HCC & $43(31 \%)$ \\
\hline $\mathrm{AFP}(\mathrm{ng} / \mathrm{ml})$ & $51.5 \pm 155.0($ range $1.4-1630.0)$ \\
\hline AFP-L3 (\%) & $8.5 \pm 13.0($ range $0-65)$ \\
\hline PIVKA II (mAU/ml) & $91.2 \pm 510.4($ range $6.0-5930.0)$ \\
\hline Tumor location & \\
\hline Subcapsular & $44(32 \%)$ \\
\hline Non-subcapsular & $94(68 \%)$ \\
\hline Kind of electrodes & \\
\hline Cool-tip & $93(67 \%)$ \\
\hline LeVeen & $45(33 \%)$ \\
\hline Ablation pattern & \\
\hline $\mathrm{R} 1$ & $78(57 \%)$ \\
\hline $\mathrm{R} 2$ & $38(27 \%)$ \\
\hline $\mathrm{R} 3$ & $22(16 \%)$ \\
\hline
\end{tabular}

LC, liver cirrhosis; $\mathrm{CH}$, chronic hepatitis; $\mathrm{HBV} / \mathrm{HCV}$, hepatitis $\mathrm{B} / \mathrm{C}$ virus; HCC, hepatocellular carcinoma. No. of tumors 138. Data are expressed as the mean (range).

was $\geq 10 \%$ in 30 lesions and $<10 \%$ in 108 lesions. The mean pre-treatment PIVKA II level was $279.4 \pm 1134.0 \mathrm{mAU} / \mathrm{ml}$ in the local recurrence group and $44.6 \pm 69.5 \mathrm{mAU} / \mathrm{ml}$ in the nonlocal recurrence group. The pre-treatment PIVKA II level was $\geq 40 \mathrm{mAU} / \mathrm{ml}$ in 34 lesions and $<40 \mathrm{mAU} / \mathrm{ml}$ in 102 lesions, and was not measured in 2 lesions. The PIVKA II level tended to be markedly elevated in the local recurrence group, but univariate analysis only showed a significant difference $(\mathrm{P}=0.0028)$ between pre-treatment AFP-L3 fraction levels $\geq 10$ and $<10 \%$.

Seventy-eight, 38 and 22 lesions showed the R1, R2, and R3 ablation patterns, respectively. A significant difference ( $\mathrm{P}=0.018$ ) was noted between the $\mathrm{R} 1$ and $\mathrm{R} 3$ ablation patterns.

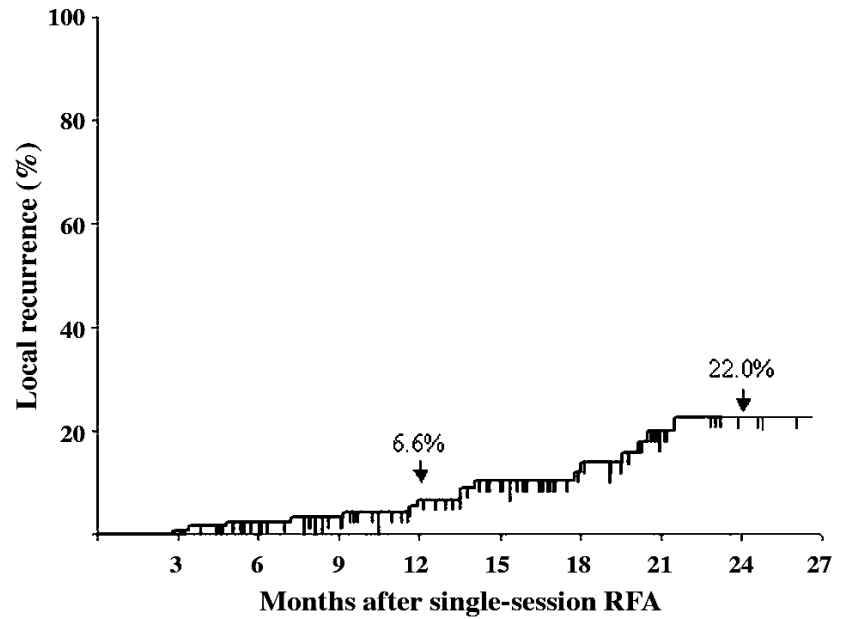

Figure 2. The local recurrence rate of hepatocellular carcinoma (HCC) after single-session RFA. The local recurrence rates were $6.6 \%$ at 1 year and $22.0 \%$ at 2 years.

Univariate analysis showed that, among the 11 variables, tumor diameter, tumor location, pre-treatment AFP-L3 fraction level and ablation pattern were significant variables (Table II). Multivariate analysis of these four variables identified only the tumor diameter as an independent risk factor for local recurrence (Table III).

Patient complications occurred in $2.2 \%$ (3/138) of all lesions: bleeding, pleural effusion, and intestinal obstruction in one case each. The treatments for these complications were an embolization, a pleural fluid drainage and a tube decompression, respectively. The post-treatment course was uneventful in all patients who were discharged after their hospital stay was prolonged by 2-3 weeks.

\section{Discussion}

RFA, first reported in 1993 by Rossi et al (19), was considered a simple low-invasive and highly effective treatment modality, and has gained popularity as a medical therapy option for HCC in recent years $(20,21)$. We previously reported that multiplesession RFA increased the risk of tumor seeding (22). Additionally, Livraghi et al (23) reported that a high number of sessions was associated with an increased incidence of serious complications, such as bleeding and tumor seeding. Seki et al (18) noted that multiple-session RFA promoted the rapid progression of HCC after RFA. Although there is no clear evidence of the rapid progression of HCC in patients undergoing multiple-session RFA, the possibility of tumor cell seeding cannot be excluded. To reduce these complications and rapid progression, we attempted to perform single-session RFA with a single electrode insertion using the Cool-tip RFA, RTC 2000 and RTC 3000 Systems.

The reported rates of local recurrence after RFA vary from one center to another depending on different RFA methods, including needle electrodes and generator operation methods, evaluation methods for therapeutic efficacy and follow-up methods. One- and 2-year recurrence rates of 1.3-24 and $2.4-36.4 \%$, respectively, have been reported $(6,8-16)$. According to reports from various centers, the 1- and 2-year 
Table II. Univariate analysis for factors contributing to local recurrence.

\begin{tabular}{lcc}
\hline Variables & Number of lesions & P-value \\
\hline Age (years) & $\geq 65(92)$ vs. $<65(46)$ & 0.9090 \\
Background of liver & LC (120) vs. CH (18) & 0.6970 \\
Etiology & HBV (13) vs. HCV (111) & 0.3990 \\
& HBV (13) vs. Other (14) & 0.3730 \\
& HCV (111) vs. Other (14) & 0.2270 \\
Child-Pugh & A (88) vs. B or C (32) & 0.0660 \\
First therapy for HCC & Yes (43) vs. No (95) & 0.6840 \\
Tumor diameter (mm) & $\geq 20(41)$ vs. <20 (97) & $<0.0001^{\mathrm{a}}$ \\
AFP (ng/ml) & $\geq 20(55)$ vs. <20 (83) & 0.9570 \\
AFP-L3 (\%) & $\geq 10(30)$ vs. $<10(108)$ & $0.0028^{\mathrm{a}}$ \\
PIVKA II (mAU/ml) & $\geq 40(34)$ vs. $<40(102)$ & 0.2990 \\
Tumor location & Subcapsular (44) vs. Non-subcapsular $(94)$ & $<0.0001^{\mathrm{a}}$ \\
Ablative margin & R1 (78) vs. R2 (38) & 0.1210 \\
& R1 (78) vs. R3 (22) & $0.0180^{\mathrm{a}}$ \\
& R2 (38) vs. R3 (22) & 0.2550 \\
\hline
\end{tabular}

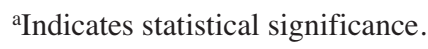

Table III. Multivariate analysis for factors independently contributing to local recurrence.

\begin{tabular}{lcc}
\hline Variables & P-value & Hazard ratio (95\% CI) \\
\hline $\begin{array}{l}\text { Tumor diameter }(\mathrm{mm}) \\
\geq 20 \text { vs. }<20\end{array}$ & $0.041^{\mathrm{a}}$ & $0.621(0.392-0.982)$ \\
$\begin{array}{l}\text { AFP-L3 (\%) } \\
\geq 10 \text { vs. }<10\end{array}$ & 0.092 & $0.666(0.414-1.069)$ \\
$\begin{array}{l}\text { Tumor location } \\
\text { Subcapsular vs. }\end{array}$ & 0.810 & $1.051(0.701-1.573)$ \\
non-subcapsular & & \\
$\begin{array}{l}\text { Ablative margin } \\
\text { R1 vs. R3 }\end{array}$ & 0.120 & $0.731(0.491-1.088)$ \\
\hline \begin{tabular}{l} 
andicates statistical significance. \\
\hline
\end{tabular}
\end{tabular}

rates of local recurrence after single-session RFA for tumors with mean diameters of $21.5-30 \mathrm{~mm}$ were $9-24$ and $10-29 \%$, respectively (8-11), and the 1- and 2-year rates of local recurrence after multiple-session RFA for tumors with mean diameters of $16-28 \mathrm{~mm}$ were $1.3-23.6$ and $2.4-36.4 \%$, respectively $(6,12-16)$, exhibiting no obvious differences in association with the number of sessions. The 1- and 2-year rates of local recurrence after single-session RFA in our hospital were 6.6 and $22.0 \%$, respectively, which were in the previously-reported range. Vincent et al (10) reported the 1and 2-year rates of local recurrence after single-session RFA using a cool-tip electrode with a 30 -mm exposed tip to be 9 and $10 \%$, respectively. Thus, the 2-year recurrence rate was lower than that in this study. This is probably because they used different approaches for RFA as needed, depending on the location and number of tumors, and included patients who had undergone laparoscopic or open RFA in their study. Komorizono et al (8) reported the 12- and 15-month cumulative local recurrence-free intervals after single-session RFA using a cool-tip electrode and LeVeen needle electrode to be 76 and $74 \%$, respectively. In their study, lesions that underwent transcatheter arterial chemoembolization (TACE) prior to RFA were included. Thus, some centers perform laparoscopic or open RFA depending on tumor location and TACE prior to RFA for hypervascular HCC. However, since patients with chronic liver disease, particularly LC, frequently have liver dysfunction, RFA under general anesthesia appears invasive. To minimize invasiveness, we make a point of performing single-session RFA with a single electrode insertion. In this study, local recurrence is defined as a case in which HCC was identified within or in contact with the ablated area during the follow-up period after RFA. Tumors smaller as well as larger than $25 \mathrm{~mm}$ are reportedly accompanied by satellite lesions $(9,24)$, which can be misdiagnosed as local recurrence. The differences in the definition of local recurrence among centers appear to be the cause of the variation in the local recurrence rate.

A tumor diameter greater than $20 \mathrm{~mm}$, a subcapsular tumor and an ablative margin less than $5 \mathrm{~mm}$ have previously been reported as risk factors for local recurrence (1,8-10, $13,14,16,25)$. A number of studies have reported that larger tumors are associated with a higher rate of local recurrence $(8-10,12,14)$. We also identified a tumor diameter of $20 \mathrm{~mm}$ or more as a significant independent factor contributing to local recurrence. 
In general, single-session RFA is considered to acheive a maximum ablated area $30 \mathrm{~mm}$ in diameter (26); however, Hori et al (9) reported that the maximum ablated area obtained by single-session RFA using RITA model 30 was $25.5 \mathrm{~mm}$ in diameter. Rossi et al (4) reported the maximum diameter of the ablated area to be $25 \mathrm{~mm}$ by single-session RFA using a single-needle electrode. It was reported that the ablated area produced by RFA conformed to the size of the tumor and was smaller than expected in the surrounding cirrhotic tissue (27). Therefore, the greatest short-axis dimension of the ablated area was less than $30 \mathrm{~mm}$ in diameter. A number of studies have recommended an ablative margin of at least $5 \mathrm{~mm}$ in RFA $(13,28)$. Considering that the ablative margin of RFA is wider than $5 \mathrm{~mm}$ based on these reports, a sufficient ablated area may not be achieved in a single session for tumors larger than $20 \mathrm{~mm}$ in diameter. Hori et al (9) reported that the rate of local recurrence after single-session RFA using RITA model 30 differed markedly depending on whether the tumor was smaller or larger than $25 \mathrm{~mm}$ in diameter; in patients with tumors smaller than $25 \mathrm{~mm}$ in diameter, the 1-, 2- and 3-year local recurrence rates were $4.0,8.0$ and $14.6 \%$, respectively, whereas in those with tumors larger than $25 \mathrm{~mm}$ in diameter, the 1-, 2- and 3-year local recurrence rates were 21.1, 32.3 and over $50 \%$, respectively. Since the possibility of the presence of satellite lesions around tumors larger than $25 \mathrm{~mm}$ is high, we consider a tumor size less than $20 \mathrm{~mm}$ in diameter to be the best indicator for single-session RFA without concomitant TACE. In this study, needle electrodes for which the maximum dimension was 30 and $35 \mathrm{~mm}$ on full expansion were also used, and wide ablated areas were achieved. However, since single-session RFA using such needle electrodes targets large tumors, treatment, including that of satellite lesions, was considered insufficient. Thus, large tumors should be carefully treated by a combination of RFA with TACE, for example, in consideration of satellite lesions.

A few studies have reported that the presence of subcapsular tumors is associated with a high rate of local recurrence after RFA $(8,9)$. This is because subcapsular lesions are difficult to visualize by US, the intercostal insertion of a needle electrode is difficult, the expansion of an expandable needle electrode is prone to be insufficient and an adequate ablative margin is difficult to secure. On the other hand, another study reported conflicting results; no significant difference was found in the local recurrence rate between subcapsular and non-subcapsular lesions (11). The non-subcapsular lesion was a significant factor for local tumor recurrence in this study. Tumors near the blood vessel are considered to be easily influenced by the cooling effect of blood flow, leading to inadequate ablative margins (12). In particular, lesions located near the second or third branches of the portal vein, a central lesion, are difficult to treat by RFA because of the cooling effect of hepatic blood flow (29-31). Therefore, nonsubcapsular lesions seem to be more subject to the vascular cooling effect. Furthermore, we sometimes encounter cases in which the RFA needle electrode cannot be advanced in the desired direction, but is erroneously inserted in the cranial or caudal direction. This is probably because the firm fibrotic liver parenchyma in patients with chronic liver disease, particularly LC, resists the insertion of the needle electrode. Thus, when performing single-session RFA, it seems easier to insert a needle electrode into the center of subcapsular than into non-subcapsular deeper lesions to obtain an adequate circumferential ablative margin. Moreover, in cases where it was difficult to visualize subcapsular lesions by US, artificial pleural or ascitic fluid was used to ensure their detection, thereby additionally enabling the safe effective RFA of subcapsular lesions.

Okusaka et al (24) reported that surgical specimens of HCC less than $30 \mathrm{~mm}$ in diameter contained small satellite lesions $5-10 \mathrm{~mm}$ away from the main tumor; therefore, it is necessary to assess whether a $5-\mathrm{mm}$ ablative margin is sufficient or not. However, since many HCC patients have underlying LC and liver dysfunction, the expansion of the ablated area by more than is necessary may further impair liver function. In this study, we noted a significant difference between the R1 and R3 ablation patterns; i.e., there was no difference between the groups in which an ablative margin greater or less than $5 \mathrm{~mm}$ was obtained around the tumor, in disagreement with previous reports. In general, CE-CT and gadolinium-enhanced MRI (Gd-MRI) were the most frequently used modalities and are regarded as the gold standard for assessing the efficacy of RFA. However, complete ablation on CE-CT and CE-MRI after RFA did not always reflect complete necrosis of the tumors on pathologic examination, particularly at the margin of the ablated area. Moreover, evaluation of therapeutic efficacy is influenced by wishful thinking. As a result, evaluation of complete ablation reportedly varies with the center (10). Therefore, the finding that there was no difference between R1 and R2 ablation patterns suggests that the actual observed image of the ablated area does not coincide with complete necrosis on pathologic examination, and that CE-CT does not accurately display the ablated area when the therapeutic effect of RFA is evaluated. It is important to perform careful follow-up using modalities including Gd-MRI and contrast-enhanced US (CE-US) as well as CE-CT, and to perform RFA to achieve an ablated area suitable for the tumor while preserving liver function.

Various centers have reported that complications due to RFA occur in $4.7-12 \%$ of cases $(13,32-34)$. In the present study, serious RFA-associated complications requiring prolonged patient hospitalization occurred for three $(2.2 \%)$ of the 138 lesions, which was slightly less frequent than reported previously (13,32-34). Although bleeding, pleural effusion, and intestinal obstruction occurred in one case each, the post-treatment course of each complication was uneventful, probably because of safe and successful treatment with single-session RFA without serious complications. A previous study reported that there was no significant difference in prognosis between patients with and without local recurrence after RFA if adequately treated (10), suggesting that it is important to perform safe RFA with few complications instead of aiming to achieve complete ablation by multiple-session RFA.

Although, in this retrospective study, a number of relatively small HCCs were treated by single-session RFA and the post-RFA follow-up period was short, this is the first study to evaluate the factors associated with local recurrence and complications with single-session RFA with a single electrode insertion for HCC using the Cool-tip RFA System and the RTC 2000 and 3000 Systems without laparoscopic RFA, open RFA and the combination of RFA with TACE. Since HCC 
patients frequently have liver dysfunction, it is important to perform appropriate RFA for the tumor diameter while preserving liver function, making single-session RFA with a single electrode insertion a good treatment option. Further follow-up of these patients, including the prognostic outcome and a comparison with patients undergoing multiple-session RFA, will clearly indicate the efficacy of single-session RFA.

In conclusion, single-session RFA is an effective treatment for HCC in that it reduces serious complications. A tumor diameter greater than $20 \mathrm{~mm}$ was identified as a significant factor for local tumor recurrence. The use of artificial pleural or ascitic fluid facilitated the effective treatment of subcapsular lesions as well. Needle electrodes applicable for larger tumors are available for the creation of large ablated areas; however, therapeutic effect cannot necessarily be assessed correctly through imaging. The presence of satellite lesions, for example larger-diameter tumors, should be treated skillfully using a combination of RFA and TACE.

\section{References}

1. Shiina S, Teratani T, Obi S, Sato S, Tateishi R, Fujishima T, Ishikawa T, Koike Y, Yoshida H, Kawabe T and Omata M: A randomized controlled trial of radiofrequency ablation with ethanol injection for small hepatocellular carcinoma. Gastroenterology 129: $122-130,2005$

2. Shiina S, Teratani T, Obi S, Hamamura K, Koike Y and Omata M: Nonsurgical treatment of hepatocellular carcinoma: from percutaneous ethanol injection therapy and percutaneous microwave coagulation to radiofrequency ablation. Oncology 62: 64-68, 2002 .

3. Livraghi T, Giorgio A, Marin G, Salmi A, Sio I, Bolondi L, Pompili M, Brunello F, Lazzaroni S, Torzilli G and Zucchi A Hepatocellular carcinoma and cirrhosis in 746 patients: longterm results of percutaneous ethanol injection. Radiology 197: 101-108, 1995.

4. Rossi S, Buscarini E, Garbagnati F, Di Stasi M, Quaretti P, Rago M, Zangrandi A, Andreola S, Silverman D and Buscarini L: Percutaneous treatment of small hepatic tumors by an expandable RF needle electrode. Am J Roentgenol 170: 1015-1022, 1998.

5. Poon RT, Fan ST, Tsang FH and Wong J: Locoregional therapies for hepatocellular carcinoma: a critical review from surgeon's perspective. Ann Surg 235: 466-486, 2002.

6. Tateishi R, Shiina S, Teratani T, Obi S, Sato S, Koike Y, Fujishima T, Yoshida H, Kawabe T and Omata M: Percutaneous radiofrequency ablation for hepatocellular carcinoma. Cancer 103: 1201-1209, 2005

7. Buscarini E, Savoia A, Brambilla G, Menozzi F, Reduzzi L, Strobel D, Hansler J, Buscarini L, Gaiti L and Zambelli A: Radiofrequency thermal ablation of liver tumors. Eur Radiol 15: 884-894, 2005.

8. Komorizono Y, Oketani M, Sako K, Yamasaki N, Shibatou T, Maeda M, Kohara K, Shigenobu S, Ishibashi K and Arima T: Risk factors for local recurrence of small hepatocellular carcinoma tumors after a single session, single application of percutaneous radiofrequency ablation. Cancer 97: 1253-1262, 2003.

9. Hori T, Nagata K, Hasuike S, Onaga M, Motoda M, Moriuchi A, Iwakiri $\mathrm{H}$, Uto $\mathrm{H}$, Kato J, Ido A, Hayashi $\mathrm{K}$ and Tsubouchi $\mathrm{H}$ : Risk factors for the local recurrence of hepatocellular carcinoma after a single session, of percutaneous radiofrequency ablation. J Gastroenterol 38: 977-981, 2003.

10. Lam VW, Ng KK, Chok KS, Cheung T-T, Yuen J, Tung H, Tso W-K, Fan S-T and Poon RT: Risk factors and prognostic factors of local recurrence after radio-frequency ablation of hepatocellular carcinoma. J Am Coll Surg 207: 20-29, 2008.

11. Poon RT, Ng KK, Lam C-M, Ai V, Yuen J and Fan S-T: Radiofrequency ablation for subcapsular hepatocellular carcinoma. Ann Surg Oncol 11: 281-289, 2004

12. Yu HC, Cheng JS, Lai KH, Lin CP, Lo GH, Lin CK, Hsu PI, Chan HH, Lo CC, Tsai WL and Chen WC: Factors for early tumor recurrence of single small hepatocellular carcinoma after percutaneous radiofrequency ablation therapy. World $\mathbf{J}$ Gastroenterol 11: 1439-1444, 2005.
13. Nakazawa T, Kokubu S, Shibuya A, Ono K, Watanabe M, Hidaka H, Tsuchihashi T and Saigenji K: Radiofrequency ablation of hepatocellular carcinoma: correlation between local tumor progression after ablation and ablative margin. Am J Roentgenol 188: 480-488, 2007.

14. Murakami T, Ishimaru H, Sakamoto I, Uetani M, Matsuoka Y, Daikoku M, Honda S, Koshiishi T and Fujimoto T: Percutaneous radiofrequency ablation and transcatheter arterial chemoembolization for hypervascular hepatocellular carcinoma: rate and risk factors for local recurrence. Cardiovase Intervent Radiol 30: 696-704, 2007.

15. Riccard L, Dania C, Laura C, Chiara F, Clotilde DP, Jacopo L and Carlo B: Early-stage hepatocellular carcinoma in patients with cirrhosis: long-term results of percutaneous image-guided radiofrequency ablation. Radiology 234: 961-967, 2005.

16. Teratani T, Yoshida H, Shiina S, Obi S, Sato S, Tateishi R, Mine N, Kondo Y, Kawabe T and Omata M: Radiofrequency ablation for hepatocellular carcinoma in so-called high-risk locations. Hepatology 43: 1101-1108, 2006.

17. Llovet JM, Vilana R, Bru C, Bianchi L, Salmeron JM, Boix L, Ganau S, Sala M, Pages M, Ayuso C, Sole M, Rodes J, Bruix J and Barcelona Clinic Liver Cancer (BCLC) Group: Increased risk of tumor seeding after percutaneous radiofrequency ablation for single hepatocellular carcinoma. Hepatology 33: 1124-1129, 2001.

18. Seki T, Tamai T, Ikeda K, Imamura M, Nishimura A, Yamashiki N, Nakagawa T and Inoue K: Rapid progression of hepatocellular carcinoma after transcatheter arterial chemoembolization and percutaneous radiofrequency ablation in the primary tumour region. Eur J Gastroenterol Hepatol 13: 291-294, 2001.

19. Rossi S, Fornaria F and Buscarini L: Percutaneous ultrasoundguided radiofrequency electrocautery for treatment of small hepatocellular carcinoma. J Intervent Radiol 8: 97-103,1993.

20. Rossi S, Di Stasi M, Buscarini E, Cavanna L, Quaretti P, Squassante E, Garbagnati F and Buscarini L: Percutaneous radiofrequency interstitial thermal ablation in the treatment of small hepatocellular carcinoma. Cancer J Sci Am 1: 73-81, 1995.

21. Curley SA, Izzo F, Delrio P, Ellis LM, Granchi J, Vallone P, Fiore F, Pignata S, Daniele B and Cremona F: Radiofrequency ablation of unresectable primary and metastatic hepatic malignancies: results in 123 patients. Ann Surg 230: 1-8, 1999.

22. Shiozawa K, Watanabe M, Wakui N, Ikehara T, Iida K and Sumino Y: Analysis of patients with tumor seeding after percutaneous radiofrequency ablation of hepatocellular carcinoma. Mol Med Rep 1: 851-855, 2008.

23. Livraghi T, Solbiati L, Meloni MF, Gazelle GS, Halpern IF and Goldberg N: Treatment of focal liver tumors with percutaneous radiofrequency ablation: complications encountered in a multicenter study. Radiology 226: 441-451, 2003.

24. Okusaka T, Okada S, Ueno H, Ikeda M, Shimada K, Yamamoto J, Kosuge T, Yamasaki S, Fukushima N and Sakamoto M: Satellite lesions in patients with small hepatocellular carcinoma with reference to clinicopathologic features. Cancer 95: 1931-1937, 2002.

25. Horiike N, Iuchi H, Ninomiya T, Kawai K, Kumagi T, Michitaka K, Masumoto T and Onji M: Influencing factors for recurrence of hepatocellular carcinoma treated with radiofrequency ablation. Oncol Rep 9: 1059-1062, 2002.

26. De Baere T, Denys A, Johns WB, Lassau N, Kardache M, Vilgrain V, Menu Y and Roche A: Radiofrequency liver ablation: experimental comparative study of water-cooled versus expandable systems. Am J Roentgenol 176: 187-192, 2001.

27. Abe T, Shinzawa H, Wakabayashi H, Aoki M, Sugahara K, Iwaba A, Haga H, Miyano S, Terui Y, Mitsuhashi H, Watanabe H, Matsuo T, Saito K, Saito T, Togashi H and Takahashi T: Value of laparoscopic microwave coagulation therapy for hepatocellular carcinoma in relation to tumor size and location. Endoscopy 32: 598-603, 2000.

28. Goldberg SN, Grassi CJ, Cardella JF, Charboneau JW, Dodd GD III, Dupuy DE, Gervais D, Gillams AR, Kane RA, Lee FT Jr, Livraghi T, McGahan J, Phillips DA, Rhim H, Silverman SG and Society of Interventional Radiology Technology Assessment Committee: Image-guided tumor ablation: standardization of terminology and reporting criteria. J Vasc Interv Radiol 16: 765-778, 2005.

29. Rossi S, Di Stasi M, Buscarini E, Quaretti P, Garbagnati F, Squassante L, Paties CT, Silverman DE and Buscarini L: Percutaneous RF interstitial thermal ablation in the treatment of hepatic cancer. Am J Roentgenol 167: 759-768, 1996. 
30. Solbiati L, Goldberg SN, Ierace T, Livraghi T, Meloni F, Dellanoce M, Sironi S and Gazelle GS: Hepatic metastases: percutaneous radio-frequency ablation with cooled-tip electrodes. Radiology 205: 367-373, 1997.

31. Shibata T, Iimuro Y, Yamamoto Y, Maetani Y, Ametani F, Itoh K and Konishi J: Small hepatocellular carcinoma: comparison of radio-frequency ablation and percutaneous microwave coagulation therapy. Radiology 223: 331-337, 2002.

32. Muilier S, Muilier P, Ni Y, Miao Y, Dupas B, Marchal G, De Wever I and Michel L: Complications of radiofrequency coagulation of liver tumors. Br J Surg 89: 1206-1222, 2002.
33. Buscarini E and Buscarini L: Radiofrequency thermal ablation with expandable needle of focal liver malignancies: complication report. Eur Radiol 14: 31-37, 2004.

34. De Baere T, Risse O, Kuoch V, Dromain C, Sengel C, Smayra T, Gamal M, Letoublon C and Elias D: Adverse events during radiofrequency treatment of 582 hepatic tumors. Am J Roentgenol 181: 695-700, 2003. 
